\title{
Postoperative Management of Shivering: A Comparison of Pethidine vs. Ketamine
}

\author{
Mahmood Eydi ${ }^{1}$; Samad EJ Golzari ${ }^{2,}$; Davood Aghamohammadi ${ }^{1}$; Khosro Kolahdouzan ${ }^{3}$; \\ Saeid Safari ${ }^{4}$; Zohreh Ostadi ${ }^{1}$ \\ ${ }^{1}$ Department of Anesthesiology, Tabriz University of Medical Sciences, Tabriz, Iran \\ 2 Liver and Gastrointestinal Disease Research Center, Tabriz University of Medical Sciences, Tabriz, Iran \\ ${ }_{4}^{3}$ Faculty of Paramedical, Tabriz University of Medical Sciences, Tabriz, Iran \\ ${ }^{4}$ Department of Anesthesiology, Rasoul Akram Medical Center, Iran University of Medical Sciences (IUMS), Tehran, Iran \\ *Corresponding author: Samad EJ Golzari, Liver and Gastrointestinal Disease Research Center, Tabriz University of Medical Sciences, Tabriz, Iran. Tel: +98-9141151894, Fax: +98- \\ 4113367373, E-mail:dr.golzari@hotmail.com
}

Received: October 19, 2013; Revised: November 17, 2013; Accepted: November 28, 2013

\begin{abstract}
Background: One of the unpleasant side effects of general anesthesia is shivering in the process of recovery. It is an involuntary oscillatory mechanical movement that can be classified as clonic movements. These movements can affect one or several groups of skeletal muscles beginning from 5 to 30 minutes after the discontinuation of anesthesia.

Objectives:Weaimed to study ketamine's effect on shivering after operation compared to pethidine as a way for treatment of postoperative shivering.

Patients and Methods: In this study, 60 patients who underwent ENT surgery with general anesthesia and had shivering during recovery were randomly divided into two groups of 30 patients each receiving ketamine $(0.2 \mathrm{mg} / \mathrm{kg} \mathrm{IV})$ and pethidine $(0.5 \mathrm{mg} / \mathrm{kg})$.

Results: There was no statistically significant difference between the shivering intensity in both groups. Only regarding the shivering in the first minute after entering the recovery room, there was an obvious difference between ketamine and pethidine groups which was again not statistically significant $(\mathrm{P}=0.07)$.

Conclusions: The results of this study showed that ketamine and pethidine are both equally effective in the reduction of postoperative shivering.
\end{abstract}

Keywords:Shivering; Ketamine; Meperidine; Anesthesia; Pethidine

\section{Background}

Management of patients' complaints has always been of priority for the physicians (1-3). Post-operative complications are major causes of the morbidity in surgical patients (4-6). Shivering, asynchronous and random spontaneous contractions of skeletal muscles to increase basal metabolism, is an important defense mechanism for temperature regulation in adults (7). Shivering is one of the unpleasant complications during recovery from anesthesia manifesting as involuntary oscillatory mechanical movements and can be characterized as clonic movements starting from 5 to 30 minutes after the cessation of anesthesia (7). Although it is unclear what percentage of the patients experience shivering, its occurrence has been reported to vary from $5 \%$ to $66 \%$ in patients recovering from anesthesia. Post-operative shivering in patients severely increases oxygen consumption (400 times) which is followed by a rise in $\mathrm{CO}_{2}$ production leading to acidosis when the alveolar ventilation is not increased proportionally (7). Not only anesthetic drugs impair normal body temperature regulation but also patients under general anesthesia are exposed to cold temperature. Heat intemperance is increased by vasoconstriction inhibition, decreased metabolic rate and shivering is inhibited by anesthetic agents and muscle relaxants. Although its mechanism of action is not completely understood, pethidine probably acts directly on the thermoregulatory centre or via opioid receptors. It is likely that N-methyl-d-aspartate (NMDA) receptor antagonists also modulate thermoregulation at multiple levels. Like morphine, pethidine exerts its analgesic effects by acting as an agonist at the $\mu$-opioid receptor (8). It also has an agonistic $\kappa$-opioid receptor action, which may be involved in the anti-shivering effects it elicits $(9,10)$.

Ketamine, derived from phencyclidine, is an agent used in dissociative anesthesia and characterized by thalamus and limbic system separation on the electroencephalograph (EEG). Fast acting and fat solubility of ketamine guarantee its rapid onset. Similar to single intravenous 
dose of other intravenous anesthetics, ketamine's effect ends by its diffusion to passive tissues. The major metabolite of ketamine, norketamine is less powerful than ketamine and is excreted to the urine (8). Ketamine has characteristics such as induction of amnesia, cerebral vasodilatation, and ICP increase, marked and transient increase in blood pressure by stimulating sympathetic system, bronchial smooth muscle relaxation, analgesia and hallucination. Ketamine, which is a competitive NMDA receptor antagonist, has been shown to inhibit postoperative shivering in some reports and studies (11-13). Ketamine induction dose is $1-2 \mathrm{mg} / \mathrm{kg}$ as IV or $4-6 \mathrm{mg} / \mathrm{kg} \mathrm{IM}$. Low doses of Ketamine (0.2 to 0.8 ) are used for analgesia by some practioners. Ketamine provides effective analgesia without compromising the airway (7). Side effects of ketamine are mostly seen in high doses. Side effects have not been reported when ketamine was used at $0.5 \mathrm{mg} / \mathrm{kg}$ about 20 minutes before the end of surgery or general anesthesia.

\section{Objectives}

We aimed to study ketamine's effect on shivering after operation compared to Pethidine as a way for treatment of postoperative shivering.

\section{Patients and Methods}

After obtaining approval of the Ethical Committee of Tabriz University of Medical Sciences and informed written consent from patients, 60 subjects with ASA class or II undergoing rhinoplasty under general anesthesia who experienced post-operative shivering were selected randomly and divided into two groups (each group $30 \mathrm{pa}-$ tient), one group receiving ketamine $(0.2 \mathrm{mg} / \mathrm{kg}$ IV) and other pethidine $(0.5 \mathrm{mg} / \mathrm{kg})$. To determine the sample size, online software was used (please see: http://www. stat.ubc.ca/ rollin/stats/size/). Simple randomization method was used in order to randomize the patients into two groups. Inclusion criteria were as follows: ENT surgeries under general anesthesia, patients with ASA class I or II, operation duration of 1-2 hours, occurrence of peri-operative shivering. Exclusion criteria were: patients with ASA class III or higher, emergency operations and patients with a history of shivering or thermal disorders.

For induction of anesthesia, midazolam ( $2 \mathrm{mg}$ ), fentanyl $(1-2 \mu \mathrm{g} / \mathrm{kg})$ and propofol $(3 \mathrm{mg} / \mathrm{kg})$ were used in all patients and atropine $(0.5 \mathrm{mg})$ and neostigmine $(1.5 \mathrm{mg})$ were used at the end of operation for neuromuscular blockade antagonization. Duration of surgery, amount of infused fluid and blood loss throughout the procedures were noted. The axillary temperature was measured for all patients. Operation room temperature was maintained at $22^{\circ} \mathrm{C}$. Patients' shivering was graded in the recovery room and 60 patients were studied with postoperative shivering. Shivering of patients was grouped into five grades; grade 0: lack of shivering, grade I: slight shivering (inconsiderable yet apparent peripheral vaso- constriction), grade II: medium level shivering (muscular activity in one muscle group only), grade III: severe shivering (muscular activity in more than one muscle group without generalized shivering), grade IV: generalized shivering.

All patients in the recovery room received a blanket and oxygen by facial mask ( $4 \mathrm{~L} / \mathrm{min})$. Patients with shivering in the recovery room were randomly divided into two groups of 30 patients and in one group pethidine $(0.5$ $\mathrm{mg} / \mathrm{kg})$ and in the second group Ketamine $(0.2 \mathrm{mg} / \mathrm{kg})$ were used. Due to the high incidence of postoperative shivering no control group was utilized. Drugs diluted into a volume of $2 \mathrm{~mL}$ in coded syringes were injected by anesthesiologists that did not know either patients' management details or their shivering grade. Shivering grade was evaluated before ( $0 \mathrm{~min}$ ) and every minute until 10 minutes after the treatment. Arterial oxygen saturation, heart rate and non-invasive blood pressure (systolic, diastolic and mean arterial blood pressure) of patients were recorded before and after treatment every minute for 10 minutes. Patients' temperature was measured immediately before treatment (zero minute) and 5 and 10 minutes after the treatment. Possible side effects associated with drug like nausea, vomiting, hypotension, hypertension, tachycardia, nystagmus, sense of walking in the air and hallucination was recorded. All variables were analyzed by SPSS 16 software. Descriptive statistical methods (frequency, percentage and mean \pm SD) were used for the statistical evaluation. Chi square test was used for the comparison of qualitative findings. P value less than 0.05 was considered significant in the study.

\section{Results}

Patients in both groups were in 15 to 55 years old age range. There were no statistically significant differences regarding the gender, weight and physical condition (ASA) between the two groups (Table 1).

The measured axillary temperature for the patients in Groups $\mathrm{K}$ and P were $36.85 \pm 0.28{ }^{\circ} \mathrm{C}$ and $37.05 \pm 0.27$ ${ }^{\circ} \mathrm{C}$, respectively. The mean liquid volume administered throughout the procedures for the patients in Groups $\mathrm{K}$ and $\mathrm{P}$ were $1500 \pm 500 \mathrm{~mL}$ and $1440 \pm 400 \mathrm{~mL}$, respectively. Mean systolic blood pressure of patients in the ketamine group was $123 \pm 28 \mathrm{mmHg}$ and mean diastolic blood pressure in these patients was $78.6 \pm 13.56 \mathrm{~mm} \mathrm{Hg}$. Average pulse rate in patients was $97 \pm 13$ beats per minute, the average respiratory rate was $15.5 \pm 1.5$ breaths per minute, the average body temperature of patients was $36.85 \pm 0.28^{\circ} \mathrm{C}$, the mean arterial oxygen saturation $\left(\mathrm{SaO}_{2}\right)$ in patients was $97.75 \pm 1.18 \%$. Mean anesthesia duration in the ketamine group was $128 \pm 43 \mathrm{~min}$ (Table 2). All these 30 patients received $1-2 \mu \mathrm{g} / \mathrm{kg}$ fentanyl. For the management of anesthesia in this group patients were anesthetized by propofol with a relaxant (cis-atracurium).

In this group of patients, nine patients (30\%) had nausea, eight patients (26.7\%) had tachycardia, two patients 
Eydi Met al.

(6.7\%) had nausea and tachycardia and one patient had vomiting while 10 patients (33.3\%) had no side effects except shivering (Table 3). The fluid therapy throughout the operation: $80 \%$ of patients received Ringer and only $20 \%$ received normal saline. Mean volume of the received fluid was $1.5 \pm 0.5$ liter and minimum and maximum injected fluid volumes were 1 and 2.5 liters, respectively.

Sedation rate of all patients was evaluated moments after entering the recovery room (time zero), 10 minutes, 30 minutes and 45 minutes with 5 grades from zero to 4 ; alert status was recorded as Grade 0 , waking up to sound as Grade 1, waking up with verbal command as grade 2, waking up with touching stimulation as grade 3, no response to sever stimulation as grade 4 . Consequently, in the ketamine group, 9 patients (30\%) were in Grade 2, 7 patients (23.3\%) were in grade 4 and 14 patients (46.7\%) were in Grade 3 at the time of entering recovery. Level of consciousness in patients was determined 10 minutes after the arrival of the patient in the recovery room, at this time 13 patients (43.3\%) were in grade 3,15 patients $(50 \%)$ in grade 2 , and 2 patients (6.7\%) in grade 1 . Sedation levels 30 minutes after arrival in the recovery room were categorized as below: 21 patients (70\%) in Grade 1, 6 patients (20\%) in Grade 2 and eventually 3 patients (10\%) in grade 0 . All patients were fully alert after 45 minutes and were classified as grade zero.

Mean systolic blood pressure in the pethidine group was $123 \pm 28 \mathrm{mmHg}$ and mean diastolic blood pressure was $74.06 \pm 12.81 \mathrm{mmHg}$. Mean pulse rate in patients was $96 \pm$ 12 beats per minute, mean RR $15.5 \pm 1.5$ breaths per minute and mean temperature $37.05 \pm 0.27^{\circ} \mathrm{C}$, respectively. Mean arterial oxygen saturation $\left(\mathrm{SaO}_{2}\right)$ was $92.06 \pm 1.92 \%$. Mean duration of anesthesia in the pethidine group was $144 \pm$ $41 \mathrm{~min}$ (Table 2). All these 30 patients had received 1-2 $\mu \mathrm{g} /$ $\mathrm{kg}$ fentanyls preoperatively like the ketamine group and for all patients the same type of anesthetic drug (propofol) and relaxant (cis-atracurium) were administered for anesthesia maintenance. In the pethidine group, 12 patients (40\%) had nausea, 6 patients (20\%) tachycardia, 5 patients (16.7\%) nausea and tachycardia and 1 patient (3.3\%) vomiting; 6 patients did not have any complication except shivering (Table 3). Eighty four percent of patients received ringer and only $16 \%$ of them got normal saline. Mean fluid intake during operation was $1.44 \pm 0.45$ in the pethidine group.

Sedation rate of these patients after entering into the recovery room was 12 patients in grade $2(40 \%), 13$ patients in grade $3(43.3 \%)$ and 5 patients grade $4(16.7 \%)$. Level of consciousness in patients was determined 10 minutes after the arrival into the recovery and at this time 11 patients $(36.7 \%)$ were in grade 2,9 patients $(30 \%)$ in grade 3,8 patients (26.7\%) in grade 1 and 2 patients in grade 4 (6.7\%). Sedation levels 30 minutes after arrival to the recovery were categorized as below: 14 patients (46.7\%) in Grade 1,10 patients (33.3\%) in Grade 0 and eventually 6 patients $(20 \%)$ in grade 2 . Seventy percent of patients were fully alert after 45 minutes and were classified as grade zero and $30 \%$ were in grade 1 . Shivering of patients was evaluated and grouped in five grades (from 0 to 4 ) every minute until 10 minutes as below; Grade 0: lack of shivering, grade I: slight but apparent shivering, grade II: muscular

Table 1. Demographic Characteristics and Physical Condition of Patients in the Ketamine and Pethidine Groups ${ }^{\mathrm{a}, \mathrm{b}}$

\begin{tabular}{lccc}
\hline Variable & Ketamine Group & Pethidine Group & P Value \\
\hline Age, $\mathbf{y}$ & $29.33 \pm 12$ & $30.5 \pm 10.5$ & 0.27 \\
Sex & & & \\
Woman & $15(50)$ & $15(50)$ & - \\
Man & $15(50)$ & $15(50)$ & - \\
Weight, kg & $10 \pm 65$ & $68 \pm 7.5$ & 0.24 \\
ASA & & & \\
\multicolumn{1}{c}{ Class I } & 27 & 26 & 0.74 \\
Class II & 3 & 4 & 0.66 \\
\hline
\end{tabular}

a Abbreviation: ASA, American Society of Anesthesiologists.

$\mathrm{b}$ Data are presented as mean \pm SD or No. (\%).

Table 2. Mean and Standard Deviation of Systolic and Diastolic Blood Pressure, Pulse Rate, Respiratory Rate, Temperature, Arterial Oxygen Saturation, and Duration of Anesthesia in Pethidine and Ketamine Groups

\begin{tabular}{|c|c|c|c|}
\hline & Mean \pm SD & Mean \pm SD & P Value \\
\hline $\begin{array}{l}\text { Systolic blood pressure, } \\
\text { mmHg }\end{array}$ & $28 \pm 123$ & $28 \pm 123$ & 0.86 \\
\hline $\begin{array}{l}\text { Diastolic blood pressure, } \\
\text { mmHg }\end{array}$ & $78.6 \pm 13.56$ & $\begin{array}{c}74.06 \pm \\
12.81\end{array}$ & 0.74 \\
\hline $\begin{array}{l}\text { Pulse rate, beats per } \\
\text { minute }\end{array}$ & $13 \pm 97$ & $12 \pm 96$ & 0.63 \\
\hline $\begin{array}{l}\text { Respiratory rate, breaths } \\
\text { per minute }\end{array}$ & $15.5 \pm 1.5$ & $15.5 \pm 1.5$ & 0.34 \\
\hline Body temperature, ${ }^{\circ} \mathrm{C}$ & $36.85 \pm 0.28$ & $37.05 \pm 0.27$ & 0.12 \\
\hline Arterial oxygen saturation & $97.75 \pm 1.18$ & $97.06 \pm 1.92$ & 0.65 \\
\hline $\begin{array}{l}\text { Duration of anesthesia, } \\
\text { min }\end{array}$ & $43 \pm 128$ & $41 \pm 144$ & 0.58 \\
\hline
\end{tabular}

Table 3. Nausea, Vomiting, Tachycardia, Nausea and Tachycardia and Tremor Rate in Patients upon Arrival in the Recovery Room $^{\text {a }}$

\begin{tabular}{lcc}
\hline Complication & Ketamine Group & PethidineGroup \\
\hline Nausea & $9(30)$ & $12(40)$ \\
Vomiting & $1(3.3)$ & $1(3.3)$ \\
Tachycardia & $8(26.7)$ & $6(20)$ \\
Tachycardia and & $2(6.7)$ & $5(16.7)$ \\
nausea & & $6(20)$ \\
Only shivering & $10(33.3)$ & \\
\hline a Data are presented as No.(\%).
\end{tabular}


activity in one muscle group only, grade III: muscular activity in more than one muscle group without generalized shivering, grade IV: generalized shivering.

In the ketamine group 15 patients had grade 4,14 patient grade 3 and 1 patient grade 1 shivering during start of the shivering based on the mentioned criteria; whereas 21 patient had grade 4 and 9 patient grade 3 shivering in the pethidine group. These results were not statistically different $(P=0.21)$ (Table 4$)$. In minute 5 after the start of shivering, 8 patients had grade 0,7 patients grade 1 and 2 patients grade 2 shivering in the ketamine group; also pethidine group had 6 grade 0 patients, 7 grade $1 \mathrm{pa}-$ tients and 2 grade 2 patients but the data were not statistically different $(P=0.48)$ (Table 4$)$. In minute 7 after the start of shivering, 2 patients had grade 1,1 patient grade 2 and others were without any shivering; also the pethidine group had 3 grade 1 patients and other patients were without shivering but data were not statistically different $(P=0.48)$ (Table 4$)$. Patients of both groups did not have shivering after minute 8 .

\section{Discussion}

Postoperative shivering is a common problem emerging from the general anesthesia in the recovery room that occurs in 5 to 65 percent of patients. This condition is very inconvenient for patients. Postoperative shivering is a phenomenon regulated by temperature

Table 4. The Intensity of Shivering in Patients upon Arrival in the Recovery Room, Minutes 5 and 7 in Both Ketamine and Pethidine Groups

\begin{tabular}{|c|c|c|c|}
\hline $\begin{array}{l}\text { Shivering Sever- } \\
\text { ity }\end{array}$ & $\begin{array}{l}\text { Ketamine } \\
\text { Group }\end{array}$ & $\begin{array}{l}\text { Pethidine } \\
\text { Group }\end{array}$ & PValue \\
\hline On Enterance & & & 0.21 \\
\hline Grade 0 & 0 & 0 & \\
\hline Grade 1 & 0 & 0 & \\
\hline Grade 2 & 1 & 0 & \\
\hline Grade 3 & 14 & 9 & \\
\hline Grade 4 & 15 & 21 & \\
\hline Min 5 & & & 0.86 \\
\hline Grade 0 & 8 & 6 & \\
\hline Grade 1 & 10 & 7 & \\
\hline Grade 2 & 3 & 2 & \\
\hline Grade 3 & 1 & 0 & \\
\hline Grade 4 & 0 & 0 & \\
\hline Min 7 & & & 0.48 \\
\hline Grade 0 & 0 & 0 & \\
\hline Grade 1 & 2 & 3 & \\
\hline Grade 2 & 1 & 0 & \\
\hline Grade 3 & 0 & 0 & \\
\hline Grade 4 & 0 & 0 & \\
\hline
\end{tabular}

(a physiological response to anesthesia-induced central hypothermia) or triggered by cytokine release induced by surgical procedures (14). Shivering is defined as the involuntary movement of one or more muscle groups during the first stage after general or local anesthesia. Furthermore, shivering is associated with other complications including increased oxygen consumption, decreased tissue oxygenation, increased production of carbon dioxide, lactic acidosis, increased left ventricular systolic work index, increased intraocular pressure of eye and brain, interference with ECG monitoring and fluctuations in the blood pressure (14). Pethidine is the most effective treatment for postoperative shivering. Ketamine is an anesthetic agent and non-competitive antagonist of N-methyl D-aspartate (NMDA) which in lower subanesthetic doses has analgesic effects, regulates temperature in multiple stages and prevents shivering $(15,16)$. This study showed that the use of pethidine (5 $\mathrm{mg} / \mathrm{kg})$ as opposed to the ketamine in patients $(0.2 \mathrm{mg} /$ $\mathrm{kg}$ ) has no significant beneficial effect on postoperative shivering.

Also another study reported no significant difference between ketamine and pethidine in controlling postoperative shivering; however, pethidine is the medication of choice due to the high incidence of side effects in the ketamine group $(17,18)$. In a similar study, no case of shivering was reported in the pethidine group. In addition, use of prophylactic low dose of ketamine in shivering control after anesthesia for tonsillectomy in children was more effective than pethidine (19). In another study it was found that $0.5 \mathrm{mg} / \mathrm{kg}$ ketamine was better than $0.3 \mathrm{mg}$ ketamine; however, pethidine is still the first and best choice (20). Unlike the present study, the only study on the effect of ketamine on shivering control reported that shivering was controlled after 4 minutes (21). In our study, no significant difference could be found between ketamine and pethedine anti-shivering features.

Although most studies agree with the anti-shivering effect of ketamine, pethidine is reported to be a better and more effective choice for shivering control in most of studies. Our study demonstrated that both ketamine and pethidine possess anti-shivering effects yet no significant difference exists between these agents. Considering the fact that no significant difference could be observed between both medications regarding post-operative shivering and also the fact that administration of Ketamine could be associated with some undesirable complications, the conventional administration of mepridine seems to be more logical and safer.

\section{Acknowledgements}

The authors would like to offer their special thanks to the Research Deputy of Tabriz University of Medical Sciences for its support and providing funding for this research. 


\section{Authors' Contribution}

Study concept and design: Dr. Eydi and Golzari, acquisition of data: Dr. Ostadi and Kolahdouzan, analysis and interpretation of data: Dr. Ostadi, Golzari and Kolahdouzan, drafting of the manuscript: Dr. Golzari, critical revision of the manuscript for important intellectual content: Dr. Aghamohammadi and Dr. Saeid Safari, statistical analysis: Dr. Golzari, Administrative, technical, and material support: Dr. Golzari, study supervision: Dr. Eydi and Golzari.

\section{Financial Disclosure}

We declare that the authors have no financial interests related to the material in the manuscript.

\section{Funding/Support}

This study was supported in part by the research deputy of Tabriz University of Medical Sciences.

\section{References}

1. Khodadoust K, Ardalan M, Ghabili K, Golzari SE, Eknoyan G. Discourse on pulse in medieval Persia--the Hidayat of Al-Akhawayni (?-983 A D.). Int J Cardiol. 2013;166(2):289-93.

2. Golzari SE, Khan ZH, Ghabili K, Hosseinzadeh H, Soleimanpour H, Azarfarin R, et al. Contributions of Medieval Islamic physicians to the history of tracheostomy. Anesth Analg. 2013;116(5):1123-32.

3. Golzari SE, Khodadoust K, Alakbarli F, Ghabili K, Islambulchilar Z, Shoja MM, et al. Sleep paralysis in medieval Persia - the Hidayat of Akhawayni (?-983 AD). Neuropsychiatr Dis Treat. 2012;8:229-34.

4. Sokouti M, Aghdam BA, Golzari SEJ, Moghadaszadeh M. A comparative study of postoperative pulmonary complications using fast track regimen and conservative analgesic treatment: a randomized clinical trial. Tanaffos. 2011;10(3):12-9.

5. Eydi M, Kolahdouzan K, Golzari SE. Effect of Intravenous Hydrocortisone on Preventing Postoperative Sore Throat Followed by Laryngeal Mask Airway Use in patients Undergoing Urogenital
Surgeries. J Cardiovasc Thorac Res. 2013;5(1):29-33.

6. Agamohamdi D, Hosseinzadeh H, Golzari S, Alizadeh A, Peirovyfar A, Movassaghi R, et al. Preincisional ipsilateral stellate ganglion block for acute post operative pain control in unilateral mastectomy. Pakistan Journal of Medical Sciences. 2011;27(4): 879-83.

7. Kose EA, Dal D, Akinci SB, Saricaoglu F, Aypar U. The efficacy of ketamine for the treatment of postoperative shivering. Anesth Analg. 2008;106(1):120-2.

8. Bryant B, Knights K. Pharmacology for Health Professionals. 3rd edChatswood: Mosby Australia;2010.

9. Brunton L. Goodman and Gilman's pharmacological basis of therapeutics. 12 th ed: McGraw-Hill; 2010.

10. Wrench IJ, Cavill G, Ward JE, Crossley AW. Comparison between alfentanil, pethidine and placebo in the treatment of post-anaesthetic shivering. BrJ Anaesth. 1997;79(4):541-2.

11. Park SM, Mangat HS, Berger K, Rosengart AJ. Efficacy spectrum of antishivering medications: meta-analysis of randomized controlled trials. Crit Care Med. 2012;40(11):3070-82.

12. Sharma DR, Thakur JR. Ketamine and shivering. Anaesthesia. 1990;45(3):252-3.

13. Kose EA, Honca M, Dal D, Akinci SB, Aypar U. Prophylactic ketamine to prevent shivering in parturients undergoing Cesarean delivery during spinal anesthesia. JClin Anesth. 2013;25(4):275-80.

14. Soliman MG, Gillies DM. Muscular hyperactivity after general anaesthesia. Can Anaesth Soc J.1972;19(5):529-35.

15. Smith RM, Bachman L, Bougas T. Shivering following thiopental sodium and other anesthetic agents. Anesthesiology. 1955;16(5):655-64.

16. Vaughan MS, Vaughan RW, Cork RC. Postoperative hypothermia in adults: relationship of age, anesthesia, and shivering to rewarming. Anesth Analg. 1981;60(10):746-51.

17. Cheong KF, Low TC. Propofol and postanaesthetic shivering. Anaesthesia.1995;50(6):550-2.

18. Frank SM, Fleisher LA, Olson KF, Gorman RB, Higgins MS, Breslow MJ, et al. Multivariate determinants of early postoperative oxygen consumption in elderly patients. Effects of shivering, body temperature, and gender. Anesthesiology. 1995;83(2):241-9.

19. Cohen M. An investigation into shivering following anaesthesia: preliminary report. Proc R Soc Med.1967;60(8):752-3.

20. Baker KZ, Young WL, Stone JG, Kader A, Baker CJ, Solomon RA. Deliberate mild intraoperative hypothermia for craniotomy. Anesthesiology. 1994;81(2):361-7.

21. Pflug AE, Aasheim GM, Foster C, Martin RW. Prevention of postanaesthesia shivering. Can Anaesth Soc J.1978;25(1):43-9. 